\title{
AGGLOMERATION OF DRIED ILEX PARAGUARIENSIS FOR CONSUMPTION PURPOSES
}

\author{
Marcin Jewiarz, Krzysztof Mudryk, Marek Wrobel, Anna Pociask \\ University of Agriculture in Krakow, Poland \\ marcin.jewiarz@urk.edu.pl,krzysztof.mudryk@urk.edu.pl,marek.wrobel@urk.edu.pl
}

\begin{abstract}
Nowadays, many products need to be transported long distances. The amount of material is in many cases limited by volume, especially if we take into account transport by sea. This way ready products or byproducts for beverages industry are imported from Asia, Africa or Southern America. The main streams seem to be tea and coffee, but there are other herbs. Such material is dried Ilex paraguariensis, which is used for brewing a special type of tea called Yerba Mate. Main countries, responsible for production are located in Southern America (Paraguay, Argentina and Brazil). Different than for coffee, the whole processing must be made on the place of cultivation. For transportation for long distances, densification of material seems to be a reasonable way to lower the cost of this operation. This paper presents a possibility of pressure agglomeration of Ilex paraguariensis for consumption. The impact of the agglomeration process has been analysed on the qualities of the drought product. The physical characteristics of the raw material have been determined, such as the grain size distribution and moisture content. Agglomeration tests were performed using different pressures and the study was conducted about absolute and envelope density, porosity and the Brazilian test to check the compressive strength of the pellets. As research material 4 blends available in the marked were used. The results presented in the paper show that there is a possibility of production of high quality granulates made from Ilex paraguariensis. What should be expected, the highest envelope density was obtained for the highest formation pressure. What needs to be mentioned, the pressure needed to achieve a good quality granule was even two times higher than in the case of other herbal materials. This was mainly due to stiff and tough structure of the material. Nevertheless, the results show that agglomeration of dried Yerba Mate can be an interesting form for long distance transportation.
\end{abstract}

Keywords: Yerba Mate, granulation, Brazilian test, density, porosity.

\section{Introduction}

Yerba Mate (Ilex paraguariensis) is a plant growing in the subtropical regions of South America It is mainly cultivated in Paraguay, Argentina, southern Brazil and Uruguay [1], and used for preparation of hot (often called mate) or cold (terrere) beverages[2]. The tradition of brewing Yerba Mate leafs has originated with Guarani ethnic group that inhabited the regions of South America, and drinks mate from a container called matero or calabash, fitted with so called bombilla (metal or reed straw with small holes on the end), through which the infusion is filtered from the leafs [3]. High consumption of this "herbal tea" is caused by high concentration of caffeine (similar to coffee), and that is why mate is treated as stimulant beverage[4]. What is worth to mention, many researchers proofed that Yerba Mate can be a valuable source of antioxidants [5], or could be helpful in lowering of cholesterol and triglycerides concentration in human blood [4;6] and can help reduce weight [7]. That is why popularity of this herbal tea is rapidly growing not only in America, but also in Europe and other parts of the world.

As transportation of low bulk density substances for long distances is cost consuming, prices of Yerba Mate in Europe are few times higher than in the countries of origin. That is why densification technologies could be very interesting tools to improve transport economics, as it does in production of processed form of bio and alternated fuels [8-12]. The production process is very complex and consists usually of 5 stages: harvest, blanching (flash heated over open fire for 3-10 sec), dried (in hot air or smoke) to about 10-12\% of moisture content, aging (length of this process reflects in flavour typical to different mate brands) and packing $[2 ; 13]$. Usually final product is packed to paper bags with capacity form $0,25 \mathrm{~kg}$ up to $1 \mathrm{~kg}$, loosely filled with dried, fragmented leafs and small sticks. The grain size distribution could differ with brands and regions, in which the leafs are processed [14]. Also as this material is in air dry state, its bulk density will be different, but usually at low level below $450 \mathrm{~kg} \cdot \mathrm{m}^{-3}[15]$.

This paper presents introductory research concerning agglomeration of Yerba Mate for consumption purposes. 


\section{Materials and methods}

The research presented in this paper is based on four brands of Yerba Mate available in market. What is important, selection of the brands was made according to initial assessment of the material fragmentation to choose the most varied types of materials [16].

As the material varies in fragmentation, first of all the grain size distribution analysis was performed according to procedure presented in the standard PN-EN ISO 17827-2:2016-07. Six sieves were used with the mesh size $0.5 \mathrm{~mm}, 1 \mathrm{~mm}, 1.4 \mathrm{~mm}, 2 \mathrm{~mm}, 3.15 \mathrm{~mm}, 4 \mathrm{~mm}$, and the test was performed with use of LPzE-4e sieve shaker produced by Multiserv, Poland. Next, the 50representative samples of all types of Yerba Mate were prepared with the weight $4 \mathrm{~g} \pm 0.1 \mathrm{~g}$ each. Such mass value was based on the authors' practice with Yerba Mate beverage consumption. Usually for one brew can be used $8 \mathrm{~g}$ to even $40 \mathrm{~g}$, and this value depends on many factors like matero size, brand or individual taste of the customer. Such prepared samples were then agglomerated with use of a specially designed device for batch production of agglomerates in controlled conditions. In this case the device (sleeve and mandrel with diameter of $18 \mathrm{~mm}$ ), was mounted on the Heckert EDZ-20 strength machine. Such configuration allows to determine the compaction pressure $\left(p_{c p}\right)$ according to the force $\left(F_{c p}\right)$ acting on the mandrel and cross-section area of the sleeve hole. For research purposes, several compaction pressures were selected from 20MPa to $140 \mathrm{MPa}$ (Table 1), which values were the result of previous experience of the research team with granulation of biomass. The agglomeration process consists of three phases. First, after placing the sample in the sleeve, the material was compressed with stable increase of force (similar for all samples). Next, after the target force was achieved, it was stabilized for directly 10sec, and then the force was decreased and the pellet was pulled out form the sleeve hole. Such procedure would simulate commercial agglomeration of biomaterials. After agglomeration, all samples were measured (height), and left for 24 hours. After this time all granules were measured again to determine the relaxation factor $\left(r_{24}\right)$, which describes granule elongation after 24 hours. Calculations were performed according to formula:

$$
r_{24}=\frac{h_{24}-h_{i}}{h_{i}} \cdot 100 \%
$$

where $h_{i}$ - height of the pellets just after agglomeration, $\mathrm{mm}$

$h_{24}$ - height of the pellets after 24 hour, $\mathrm{mm}$

Table 1

\section{Compaction pressured and correlated compaction forces for $18 \mathrm{~mm}$ granules}

\begin{tabular}{|c|c|}
\hline $\boldsymbol{p}_{\boldsymbol{c p}}, \mathbf{M P a}$ & $\boldsymbol{F}_{\boldsymbol{c p}}, \mathbf{k N}$ \\
\hline 20 & 5.01 \\
\hline 40 & 10.20 \\
\hline 60 & 18.80 \\
\hline 80 & 20.30 \\
\hline 100 & 25.50 \\
\hline 120 & 30.50 \\
\hline 140 & 35.60 \\
\hline
\end{tabular}

In the next stages several quantities were assessed for the granules:

- Particle density $\left(\rho_{\text {part }}\right)$ with use of GeoPyc 1360 density analyser (Micromeritics, USA)

- Absolute density $\left(\rho_{a b s}\right)$ with use of AccuPyc 1340 helium pycometer (Micromeritics, USA)

- Particle porosity $(\varphi)$ calclulated by GeoPyc according to formula[17]:

$$
\varphi=\frac{V_{p a r t}-\frac{m}{\rho_{a b s}}}{V_{p a r t}},
$$

where $V_{\text {part }}$ - volume of the particles (measured by GeoPyc), $\mathrm{cm}^{3}$

$m$ - mass of the sample, $g$

$\rho_{a b s}-$ absolute density, $\mathrm{g} \mathrm{cm}^{-3}$ 
- Tensile strength $\left(R_{c p}\right)$ with use of MTS Insight 2 strength machine (MTS, USA) according to formula[18]:

$$
R_{c p}=\frac{2 F_{n}}{\pi d h},
$$

where $F_{n}$-tensile force, $\mathrm{N}$

$d$ - diameter of the granule, $\mathrm{m}$

$h$ - height of the granule, $\mathrm{m}$

Due to the small mass of the pellets produced (10 pallets for each set brand-compaction pressure), the usual durability test cannot be made. That is why the authors assessed the tensile strength as determinant of durability.

\section{Results and discussion}

The first tests reveal that the lowest values of compaction pressure (20 MPa and 40MPa) were too small to achieve granules, which would be strong enough to further testing, what is illustrated in Fig. 1. In this case, for all mixtures granulation was started form the pressure level $60 \mathrm{MPa}$. The granules formed in a different pressure level are presented in Fig. 2.

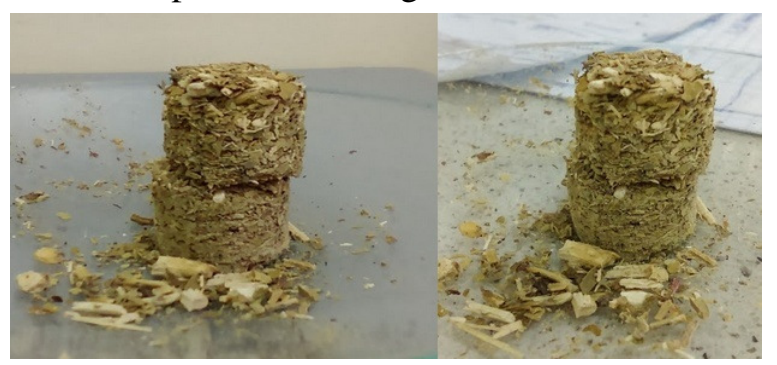

Fig. 1. Granules formed with 20MPa (left) and 40MPa (right)

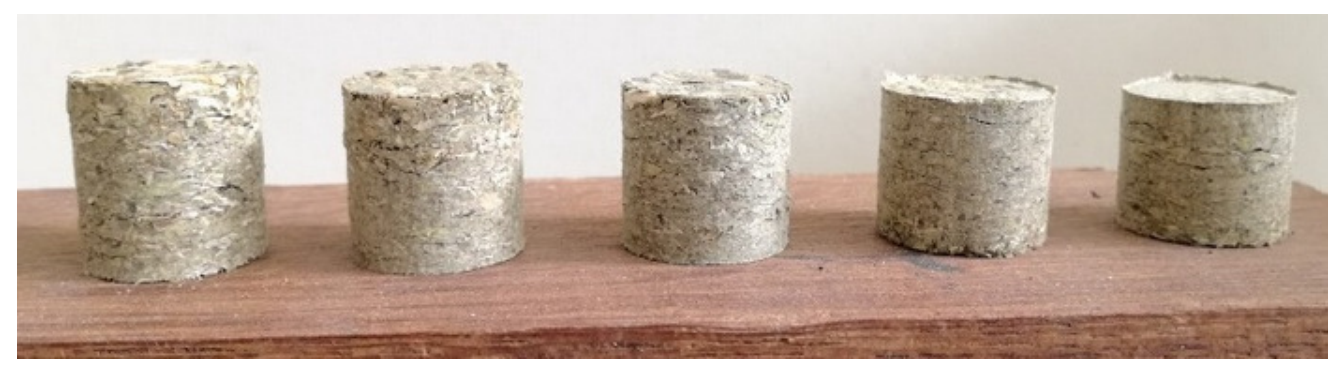

Fig. 2. Granules formed in (from left) 60, 80, 100, 120 and $140 \mathrm{MPa}$

Grain size distribution, presented in Table 1, shows that the selected brands are significantly different in fractionation. In mixtures I and IV bigger particles can be found (with diameter higher than $3.15 \mathrm{~mm}$ ). All brands contain high amounts of fine particles, below 1mm (aprox. $40 \%$ ), what seems to be typical for this material.

Table 2

\section{Grain size distribution analysis of selected Yerba Mate brands}

\begin{tabular}{|c|c|c|c|c|}
\hline \multirow{2}{*}{$\boldsymbol{d}_{\text {mesh }}, \mathbf{m m}$} & \multicolumn{5}{|c|}{$\boldsymbol{p} \boldsymbol{\%}$} \\
\cline { 2 - 5 } & I & II & III & IV \\
\hline undersieve & 17 & 26 & 23 & 22 \\
\hline 0.50 & 21 & 13 & 18 & 16 \\
\hline 1.00 & 19 & 18 & 12 & 14 \\
\hline 1.40 & 23 & 45 & 16 & 23 \\
\hline 2.00 & 8 & - & 32 & 8 \\
\hline 3.15 & 12 & - & - & 7 \\
\hline 4.00 & - & - & - & 7 \\
\hline
\end{tabular}


Analysis of the relaxation factors (Table 3) of all samples showed a tendency that mixtures with low content of coarse particles are characterised by a higher value of this parameter. This could be caused by lack of longer particles, on which skeletal structure of the granule can be build, what makes it more stiff and resistant to selfexpansion. What is interesting, the finest mixture (II) relaxation factor decreased significantly with increasing the compaction pressure.

Table 3

Relaxation factor of selected brands in correspondence to compaction pressures

\begin{tabular}{|c|c|c|c|c|}
\hline \multirow{2}{*}{$\boldsymbol{p}_{\boldsymbol{c} \boldsymbol{p}}, \mathbf{M P a}$} & \multicolumn{4}{|c|}{$\boldsymbol{r}_{\mathbf{2 4}}, \boldsymbol{\%}$} \\
\cline { 2 - 5 } & $\mathbf{I}$ & II & III & IV \\
\hline 60 & 1.77 & 9.13 & 8.72 & 2.28 \\
\hline 80 & 2.1 & 8.73 & 8.75 & 3.95 \\
\hline 100 & 3.85 & 2.62 & 7.93 & 2.33 \\
\hline 120 & 3.32 & 1.82 & 8.98 & 2.83 \\
\hline 140 & 2.86 & 0.84 & 8.12 & 3.25 \\
\hline
\end{tabular}

Analysis of the absolute densities (Table 4) showed that for all mixtures assessed the values were very similar and slightly increased with the increase of the compaction pressure, but these changes are not significant.

Table 4

Absolute density of selected brands in correspondence to compaction pressures

\begin{tabular}{|c|c|c|c|c|}
\hline \multirow{2}{*}{$\boldsymbol{p}_{\boldsymbol{c} \boldsymbol{p}}, \mathbf{M P a}$} & \multicolumn{4}{|c|}{$\boldsymbol{\rho}_{\boldsymbol{a b s}}, \mathbf{g} \cdot \mathbf{c m}^{-\mathbf{3}} \pm \mathbf{S D}$} \\
\hline & I & II & III & IV \\
\hline 60 & $1.49 \pm 0.05$ & $1.50 \pm 0.04$ & $1.48 \pm 0.03$ & $1.51 \pm 0.05$ \\
\hline 80 & $1.52 \pm 0.07$ & $1.51 \pm 0.07$ & $1.50 \pm 0.06$ & $1.52 \pm 0.06$ \\
\hline 100 & $1.55 \pm 0.08$ & $1.54 \pm 0.06$ & $1.53 \pm 0.07$ & $1.53 \pm 0.07$ \\
\hline 120 & $1.56 \pm 0.06$ & $1.57 \pm 0.05$ & $1.55 \pm 0.08$ & $1.56 \pm 0.06$ \\
\hline 140 & $1.56 \pm 0.04$ & $1.56 \pm 0.05$ & $1.55 \pm 0.05$ & $1.55 \pm 0.06$ \\
\hline
\end{tabular}

As could be predicted, the particle densities (Table 5) change significantly with the compaction pressures, and in all cases this parameter increased with the increase of the $p_{c p}$ value. What is important, only one mixture exceeds the value of $1 \mathrm{~g} \cdot \mathrm{cm}^{-3}$ (mixture IV/140MPa). In this case the profits from granulation, by lowering the transportation cost of unit mass, would be the highest.

Particle density of selected brands in correspondence to compaction pressures

Table 5

\begin{tabular}{|c|c|c|c|c|}
\hline \multirow{2}{*}{$\boldsymbol{p}_{\boldsymbol{c} p}, \mathbf{M P a}$} & \multicolumn{4}{|c|}{$\boldsymbol{\rho}_{\text {abs }}, \mathbf{g} \cdot \mathbf{c m}^{-\mathbf{3}} \pm \mathbf{S D}$} \\
\cline { 2 - 5 } & I & II & III & IV \\
\hline 60 & $0.7 \pm 0.012$ & $0.69 \pm 0.014$ & $0.7 \pm 0.002$ & $0.8 \pm 0.023$ \\
\hline 80 & $0.71 \pm 0.012$ & $0.8 \pm 0.043$ & $0.77 \pm 0.001$ & $0.9 \pm 0.014$ \\
\hline 100 & $0.72 \pm 0.091$ & $0.78 \pm 0.012$ & $0.81 \pm 0.013$ & $0.93 \pm 0.022$ \\
\hline 120 & $0.77 \pm 0.017$ & $0.83 \pm 0.014$ & $0.83 \pm 0.01$ & $0.97 \pm 0.013$ \\
\hline 140 & $0.79 \pm 0.016$ & $0.87 \pm 0.021$ & $0.9 \pm 0.038$ & $1.01 \pm 0.019$ \\
\hline
\end{tabular}

Porosity (Table 6) of all mixtures decreased with the increase in the compaction pressure, what is the result of lower volume of the particles, caused by more "packed" structure of the pellets. As in the particle densities, the lowest values were assessed to brand IV.

The tensile strength analysis shows that mostly in all cases increase of the compaction pressure results in increased durability of the pellets (in terms of tensile stress). What is important, if we compare the data presented in Fig. 3 with the particle density value (Table 5), we can see that the particle density does not affect in this type of raw material the durability of the granules, especially in low pressure ranges. Form $p_{c p}$ level of $120 \mathrm{MPa}$ the $R_{c p}$ seems to be more dependent on particle densities, but this correlation is valid only in one type of the material. In terms of tensile strength 
mixtures, III and IV have the highest values in pressure ranges above 100MPa, what could suggest that these pellets are more durable.

Table 6

Porosity factor of selected brands in correspondence to compaction pressures

\begin{tabular}{|c|c|c|c|c|}
\hline \multirow{2}{*}{$\boldsymbol{p}_{\boldsymbol{c} \boldsymbol{p}, \mathbf{M P a}}$} & \multicolumn{4}{|c|}{$\boldsymbol{\varphi , ~ \%}$} \\
\hline 60 & I & II & III & IV \\
\hline 60 & 54 & 53 & 52 & 49 \\
\hline 80 & 50 & 49 & 48 & 44 \\
\hline 100 & 48 & 48 & 47 & 44 \\
\hline 120 & 46 & 45 & 45 & 40 \\
\hline 140 & 45 & 44 & 44 & 34 \\
\hline
\end{tabular}

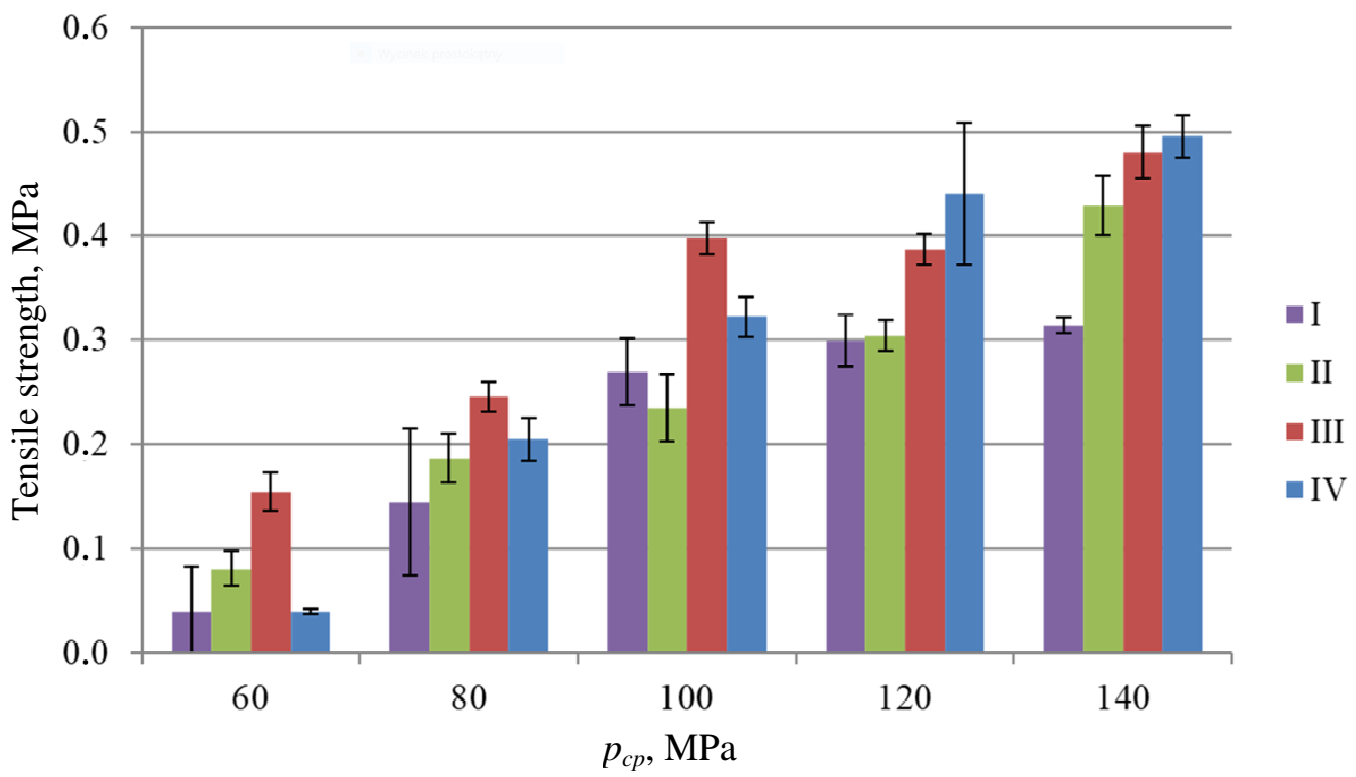

Fig. 3. Tensile strength parameter for different brands and pressures

\section{Conclusions}

1. Fractionation of Yerba Mate form different producers can be different, what visibly affects the agglomeration process.

2. Analysis of the particle density showed clearly that the best material (from the analysed samples) for granulation was brand IV, with noticeable share of bigger particles (higher than $4 \mathrm{~mm}$ ).

3. The tensile strength analysis, by means of the Brazilian test, showed that brands III and IV have the highest agglomeration potential among the analysed samples.

4. According to the presented results, agglomeration of fragmented material achieved form Ilex paraguariensis can be treated as potential material for foodstuff granulates.

\section{Acknowledgements} Poland.

This research was financed by the Ministry of Science and Higher Education of the Republic of

\section{References}

[1] Marcelo M. C. A., Martins C. A., Pozebon D., Dressler V. L. and Ferrao M. F., Classification of yerba mate (Ilex paraguariensis) according to the country of origin based on element concentrations, Microchemical Journal, vol. 117, 2014 , pp. 164-171.

[2] Heck C. I. and Mejia E. G. de, Yerba Mate Tea (Ilex paraguariensis): A Comprehensive Review on Chemistry, Health Implications, and Technological Considerations, Journal of Food Science, vol. 72, 2007 , pp. 138-151. 
[3] Junior E. L. C. and Morand C., Interest of mate ( Ilex paraguariensis A. St.-Hil.) as a new natural functional food to preserve human cardiovascular health - A review, Journal of Functional Foods, vol. 21, 2016 , pp. 440-454.

[4] Bracesco N., Sanchez A. G., Contreras V., Menini T. and Gugliucci A., Recent advances on Ilex paraguariensis research: Minireview, Journal of Ethnopharmacology, vol. 136, 2011 , pp. 378-384.

[5] Bravo L., Mateos R., Sarriá B., Baeza G., Lecumberri E., Ramos S. and Goya L., Hypocholesterolaemic and antioxidant effects of yerba mate (Ilex paraguariensis) in highcholesterol fed rats, Fitoterapia, vol. 92, 2014 , pp. 219-229.

[6] Gambero A. and Ribeiro M., The Positive Effects of Yerba Maté (Ilex paraguariensis) in Obesity, Nutrients, vol. 7, 2015 , pp. 730-750.

[7] Balzan S., Hernandes A., Reichert C. L., Donaduzzi C., Pires V. A., Gasparotto A. and Cardozo E. L., Lipid-lowering effects of standardized extracts of Ilex paraguariensis in high-fat-diet rats, Fitoterapia, vol. 86, 2013 , pp. 115-122.

[8] Wrobel M., Fraczek J., Francik S., Slipek Z., Krzysztof M. and others, Influence of degree of fragmentation on chosen quality parameters of briquette made from biomass of cup plant Silphium perfoliatum L, Conference Engineering for Rural Development, Jelgava, Latvia, 2013, pp. 653-657.

[9] Mudryk K., Fraczek J., Slipek Z., Francik S. and Wrobel M., Chosen physico-mechanical properties of cutleaf coneflower (Rudbeckia Laciniata 1.) shoots, 12th International Scientific Conference: Engineering for rural development, Jelgava, Latvia, 23-24 May 2013., Latvia University of Agriculture, 2013, pp. 658-662.

[10] Brzychczyk B., Hebda T. and Gielzecki J., Energy Characteristics of Compacted Biofuel with Stabilized Fraction of Municipal Waste, Springer Proceedings in Energy, Springer International Publishing, 2018, pp. 451-462.

[11] Brzychczyk B., Hebda T. and Gielzecki J., Physical and Chemical Properties of Pellets Produced from the Stabilized Fraction of Municipal Sewage Sludge, Springer Proceedings in Energy, Springer International Publishing, 2018, pp. 613-622.

[12] Kurpaska S. and Pedryc N., Analysis of the efficiency of a hybrid foil tunnel heating system, E3S Web of Conferences, vol. 19, 2017 , p. 01012.

[13] Schmalko M. E. and Alzamora S. M., Color, chlorophyll, caffeine, and water content variation during yerba maté processing, Drying Technology, vol. 19, 2001 , pp. 599-610.

[14] Cruz M. J. S., Garitta L. V. and Hough G., Note: Relationships of Consumer Acceptability and Sensory Attributes of Yerba Mate (Ilex Paraguariensis St. Hilarie) using Preference Mapping, Food Science and Technology International, vol. 9, 2003 , pp. 347-352.

[15] Francik S., Lapczynska-Kordon B., Francik R. and Wójcik A., Modeling and Simulation of Biomass Drying Using Artificial Neural Networks, Springer Proceedings in Energy, Springer International Publishing, 2018, pp. 571-581.

[16] Wójcik A., Przybyla W., Francik S. and Knapczyk A., The research into determination of the particle-size distribution of granular materials by digital image analysis, Springer Proceedings in Energy, Springer International Publishing, 2018, pp. 623-630.

[17] Forsmo S. P. E. and Vuori J. P., The determination of porosity in iron ore green pellets by packing in silica sand, Powder Technology, vol. 159, 2005 , pp. 71-77.

[18] Rocco C., Guinea G. V., Planas J. and Elices M., Size effect and boundary conditions in the brazilian test: theoretical analysis, Materials and Structures, vol. 32, 1999 , pp. 437-444. 